\title{
Clinicopathological characteristics and prognosis of adult ovarian granulosa cell tumor: a single- institution experience in China
}

This article was published in the following Dove Press journal:

OncoTargets and Therapy

\author{
Dan Wang \\ Yang Xiang \\ Ming Wu \\ Keng Shen \\ Jiaxin Yang \\ Huifang Huang \\ Tong Ren \\ Department of Obstetrics and \\ Gynecology, Peking Union Medical \\ College Hospital, Chinese Academy \\ of Medical Science and Peking Union \\ Medical College, Beijing, People's \\ Republic of China
}

Objectives: We aimed to demonstrate the clinical characteristics and risk factors associated with recurrence of adult granulosa cell tumor (AGCT), as well as the pregnancy and long-term outcomes among patients in a single institution in China.

Patients and methods: We reviewed 141 patients with AGCT in Peking Union Medical College Hospital between January 1983 and September 2015.

Results: The mean patient age was 45.1 years (16-78 years), and the mean tumor size was $8.8 \mathrm{~cm}(1-40 \mathrm{~cm})$. The most common symptom was irregular menstruation $(31.9 \%, \mathrm{n}=45)$. The disease distribution was stage I in 136 patients, stage II in three patients, and stage III in two patients. Eighty-seven patients (61.7\%) underwent radical surgery, while 54 (38.3\%) underwent fertility-sparing surgery, of whom five subsequently had a total of five pregnancies. Fifty-two patients underwent pelvic and/or para-aortic lymphadenectomy, and none of them showed lymph node metastasis. The median follow-up period was 72.7 months (8.9-344 months). Twenty-six patients (18.4\%) developed recurrence during the study period, with a median time to recurrence of 68 months (7-312 months). Initial stage (stage IC vs IA) and nonstaging surgery were independent risk factors for recurrence in both univariate and multivariate analyses for stage I AGCT patients.

Conclusion: Tumor stage is an independent risk factor for recurrence in patients with AGCT. Staging surgery is recommended for patients with AGCT, though lymphadenectomy may be omitted. Complete tumor resection is important for patient survival in patients with AGCT recurrence. Long-term follow-up is required, even in early-stage AGCT patients.

Keywords: granulosa cell tumor, ovary, recurrence, pregnancy

\section{Background}

Ovarian granulosa cell tumor (GCT) is a rare ovarian neoplasm derived from ovarian sex-cord stromal cells in the ovaries. GCT comprises two kinds of histology: adult granulosa cell tumor (AGCT) and juvenile granulosa cell tumor, of which AGCT accounts for $>95 \%$ of GCTs and $2 \%-5 \%$ of all ovarian malignancies. Its clinical characteristics include an indolent clinical course and later recurrence, with a better prognosis compared with ovarian epithelial cancers.

Complete tumor resection consisting of bilateral adnexectomy and hysterectomy is the standard treatment for AGCT, with adjuvant chemotherapy recommended in patients with advanced stage or stage I disease with high-risk factors (tumor rupture, high mitotic index). Fertility-sparing surgery with complete staging is recommended for young patients wishing to maintain fertility. However, experience and evidence for the optimal treatment of AGCT are limited. The rarity of AGCT means that the 
incidence of lymph node metastasis is not well known and the need for lymphadenectomy is controversial. A few previous studies have considered factors associated with AGCT recurrence, such as International Federation of Gynecology and Obstetrics (FIGO) stage, tumor rupture, tumor diameter, age, menopause, staging surgery, adjuvant chemotherapy, nuclear atypia, and mitotic rate. ${ }^{1-3}$ The purpose of the present study was to analyze the clinical characteristics and risk factors for recurrence of AGCT based on the long-term outcomes in a large series of patients treated at a single institution in People's Republic of China. In addition, we discuss the need for lymphadenectomy and the role of fertility-sparing surgery in AGCT in light of the previous studies.

\section{Patients and methods}

The study has been approved by the ethics committee of Peking Union Medical College Hospital and is in accordance with the Helsinki Declaration of 1975. Informed written consent from each patient was obtained. Medical records of all patients diagnosed with AGCT of the ovary in Peking Union Medical College Hospital from January 1983 to September 2015 were reviewed. Patients with juvenile GCT were excluded. The patients' medical records were reviewed and the following information was collected: age, menopause status, tumor diameter, serum CA125 before surgery, chief complaint, FIGO stage, type of surgery, adjuvant therapy, relapse characteristics and relapse treatment, and follow-up information. Follow-up information was obtained from outpatient files or by telephone interviews with the patients or their relatives.

Fertility-sparing surgery was defined as preservation of the uterus and at least one ovary. Total abdominal hysterectomy and bilateral salpingo-oophorectomy were classified as radical surgery. Staging surgery included peritoneal washing, peritoneal biopsy, omentectomy, pelvic and/or para-aortic lymphadenectomy, and appendectomy as optional procedures according to the surgeon's experience and the intraoperative findings.

Patients were staged according to the FIGO staging system in 2009. Patients with stage II-IV or presence of high-risk factors were given chemotherapy after surgery.

Patients were classified into a recurrence group and a nonrecurrence group. Disease-free survival was defined as the time from initial surgery to the first recurrence or censor date.

\section{Statistical analysis}

Statistical analysis was performed using SPSS version 15 (SPSS, Inc., Chicago, IL, USA). Recurrence curves were calculated using the Kaplan-Meier method and compared with log-rank tests. Two-sided $p$-values were considered statistically significant at $p<0.05$. Multivariate analysis was conducted using a Cox regression model to identify independent factors associated with recurrence. Variables with $p<0.05$ in univariate analysis were selected for multivariate analysis.

\section{Results}

A total of 141 patients underwent surgical treatment for AGCT in Peking Union Medical College Hospital during the study period. The mean age of the patients was 45.1 years (16-78 years), and 46 patients $(32.6 \%)$ were postmenopausal. The mean tumor size was $8.8 \mathrm{~cm}(1-40 \mathrm{~cm})$. The most common symptoms included irregular menstruation $(31.9 \%$, $\mathrm{n}=45)$, postmenstrual bleeding $(17.7 \%, \mathrm{n}=25)$, and abdominal pain $(16.3 \%, n=23)$. Preoperative serum CA125 levels were available for 98 patients and were elevated in 17 patients (17.3\%). The patient characteristics are listed in Table 1.

Most patients had stage I disease $(96.4 \%, n=136)$, three stage II, and two stage III. All patients underwent surgery, including fertility-sparing surgery in 54 (38.3\%) and radical surgery in 87 (61.7\%). Fifty-two patients underwent pelvic and/or para-aortic lymphadenectomy, but none showed lymph node metastasis. The surgical pathological features are given in Table 2 .

Fifty-six patients $(39.7 \%)$ received adjuvant chemotherapy after surgery, including bleomycin, etoposide, and cisplatin in 21 patients; cisplatin, vincristine, and bleomycin in nine; cisplatin and cyclophosphamide in nine; paclitaxel

Table I Characteristics of patients with AGCT

\begin{tabular}{ll}
\hline Characteristics & N (\%) \\
\hline $\begin{array}{l}\text { Age (years) } \\
\quad \leq 50\end{array}$ & $95(67.4)$ \\
$\quad>50$ & $46(32.6)$ \\
Tumor size (cm) & \\
$\quad \leq 10$ & $114(80.9)$ \\
$>10$ & $27(19.1)$ \\
Menopause & \\
$\quad$ No & $95(67.4)$ \\
Yes & $46(32.6)$ \\
Initial symptoms & \\
$\quad$ Irregular menstruation & $29(20.6)$ \\
Postmenopausal bleeding & $25(17.7)$ \\
Abdominal pain & $23(16.3)$ \\
Serum CAI25 & \\
Elevated & $17(12.1)$ \\
Normal & $81(57.4)$ \\
Not measured & $43(30.5)$ \\
\hline
\end{tabular}

Abbreviation: AGCT, adult granulosa cell tumor. 
Table 2 Surgical pathological features of patients with AGCT

\begin{tabular}{|c|c|}
\hline FIGO stage & $\mathbf{N}(\%)$ \\
\hline Stage IA & $71(50.4)$ \\
\hline Stage IC & $65(46.1)$ \\
\hline Stage II & $3(2.1)$ \\
\hline Stage III & $2(1.4)$ \\
\hline \multicolumn{2}{|l|}{ Surgical procedure } \\
\hline \multicolumn{2}{|l|}{ Fertility surgery } \\
\hline Cystectomy & $5(3.5)$ \\
\hline USO & $40(28.4)$ \\
\hline USO + staging operation & $9(6.4)$ \\
\hline \multicolumn{2}{|l|}{ Radical surgery } \\
\hline $\mathrm{H}+\mathrm{BSO}$ & $37(26.2)$ \\
\hline Staging operation & $50(35.5)$ \\
\hline \multicolumn{2}{|l|}{ Staging operation } \\
\hline Yes & $59(4 I .8)$ \\
\hline No & $82(58.2)$ \\
\hline \multicolumn{2}{|l|}{ Adjuvant therapy } \\
\hline Surgery only & $85(60.3)$ \\
\hline Surgery + chemotherapy & $56(39.7)$ \\
\hline \multicolumn{2}{|l|}{ Lymphadenectomy } \\
\hline Not performed & $89(63.1)$ \\
\hline Performed & $52(36.9)$ \\
\hline \multicolumn{2}{|l|}{ Endometrial pathology } \\
\hline Normal & $56(39.7)$ \\
\hline Endometrial polyp & $10(7.1)$ \\
\hline Simple hyperplasia & $10(7.1)$ \\
\hline Complex hyperplasia without atypia & $3(2.1)$ \\
\hline Complex hyperplasia with atypia & $3(2.1)$ \\
\hline Endometrial cancer & $2(1.4)$ \\
\hline Not measured & $57(40.4)$ \\
\hline \multicolumn{2}{|l|}{ First operation at clinical setting } \\
\hline Outer & $42(29.8)$ \\
\hline Our clinical & $99(70.2)$ \\
\hline \multicolumn{2}{|l|}{ Surgical approach } \\
\hline Laparoscopy & $54(38.3)$ \\
\hline Laparotomy & $87(6 \mid .7)$ \\
\hline
\end{tabular}

Abbreviations: AGCT, adult granulose cell tumor; FIGO, International Federation of Gynecology and Obstetrics; H + BSO, total abdominal hysterectomy and bilateral salpingo-oophorectomy; USO, unilateral salpingo-oophorectomy.

and carboplatin in five; cisplatin, adriamycin, and cyclophosphamide in four; and other regimens in eight patients.

Of the 54 patients who received fertility-sparing surgery, five underwent unilateral cystectomy, 40 underwent unilateral salpingo-oophorectomy, and nine underwent staging operations. Five of the 54 patients subsequently resulted in a total of five pregnancies. All patients had stage I disease and delivered healthy babies at term.

Endometrial evaluation was available for $84(59.6 \%)$ patients, and the results showed endometrial polyps in 10(7.1\%), simple hyperplasia in $10(7.1 \%)$, complex hyperplasia without atypia in three $(2.1 \%)$, complex hyperplasia with atypia in three (2.1\%), and endometrial cancer in two (1.4\%).

The median follow-up time was 72.7 months (8.9-344 months), during which 26 patients (18.4\%) suffered recurrence.
The mean age of the patients with recurrence was 40.2 years (27-58 years). The mean time from initial surgery to relapse was 68 months (7-312 months), including 12 patients (46.2\%) who suffered recurrences $>5$ years after their initial diagnosis.

The most common location for recurrence was the pelvic cavity $(69.2 \%, \mathrm{n}=18)$. Fourteen patients suffered one recurrence and 12 patients suffered more than one recurrence, with a maximum of seven recurrences. The longest period from initial diagnosis to recurrence was 26 years.

Treatments for recurrence included surgery alone in five patients, surgery and chemotherapy in 18 , surgery and chemoradiation in two, and surgery and radiofrequency ablation in one patient.

Sixteen patients were alive without evidence of disease at the last follow-up, four were alive with disease, two had died as a result of recurrence, three were lost to follow-up, and one patient was receiving therapy.

More than $95 \%$ of the patients had stage I disease, and we therefore defined relapse factors for stage I disease. The clinicopathological factors associated with disease-free survival in 136 patients with stage I AGCT are shown in Table 3. In univariate analysis, recurrence was associated with stage IC and nonstaging surgery ( $p=0.01,0.041)$ (Figure 1A and B), while multivariate analysis also identified stage IC and nonstaging surgery as independent risk factors for recurrence (hazard ratio $=3.839,95 \%$ confidence interval $=1.430-10.309$, hazard ratio $=2.673,95 \%$ confidence interval $=1.092-6.543$ ).

\section{Discussion}

We investigated the prognostic significance of risk factors including age, menopausal status, tumor size, surgical method, FIGO stage, and adjuvant chemotherapy for recurrence in patients with AGCT. Both univariate and multivariate analyses identified FIGO stage and surgical method as significant prognostic factors.

FIGO stage is the most widely accepted risk factor for recurrence in patients with AGCT, and several studies have shown correlations between higher disease stage and increased recurrence. ${ }^{4,5}$ The 5 -year survival was reported to be $75 \%-95 \%$ in patients with early-stage disease, and this fell to $25 \%-50 \%$ in patients with advanced-stage disease. In the present study, $>95 \%$ of patients presented with stage I disease, and we therefore analyzed the risk factors for recurrence in stage I disease. Our results also identified initial FIGO stage at diagnosis as an independent risk factor for recurrence. 
Table 3 Risk factors for recurrence in stage I AGCT

\begin{tabular}{|c|c|c|c|c|c|}
\hline \multirow[t]{2}{*}{ Factors } & \multirow{2}{*}{$\begin{array}{l}\text { Recurrence } \\
\text { rate }(\%)\end{array}$} & \multicolumn{2}{|l|}{ Univariate } & \multicolumn{2}{|l|}{ Multivariate } \\
\hline & & HR (95\% Cl) & $p$-value & HR (95\% Cl) & $p$-value \\
\hline Age (years) & & & 0.202 & & \\
\hline$\leq 50$ & $22.0(20 / 91)$ & 1 & & & \\
\hline$>50$ & II.I (5/45) & $0.526(0.196-1.4 I 2)$ & & & \\
\hline Menopause & & & 0.169 & & \\
\hline Yes & II.I (5/45) & I & & & \\
\hline No & $22.0(20 / 91)$ & $2.000(0.745-5.370)$ & & & \\
\hline Size $(\mathrm{cm})$ & & & 0.234 & & \\
\hline$\leq 10$ & $20.5(23 / I / 2)$ & I & & & \\
\hline$>10$ & $8.3(2 / 24)$ & $0.415(0.097-1.766)$ & & & \\
\hline Surgery & & & 0.041 & & 0.031 \\
\hline Staging & $12.5(7 / 56)$ & I & & I & \\
\hline Unstaged & $22.5(18 / 80)$ & $2.544(1.038-6.234)$ & & $2.673(1.092-6.543)$ & \\
\hline FIGO stage & & & 0.01 & & 0.008 \\
\hline IA & $7.0(5 / 7 I)$ & I & & 1 & \\
\hline IC & $26.7(20 / 65)$ & 3.689 (1.375-9.894) & & $3.839(1.430-10.309)$ & \\
\hline Adjuvant therapy & & & 0.319 & & \\
\hline Yes & $17.0(9 / 53)$ & I & & & \\
\hline No & $19.3(16 / 83)$ & $0.65 \mid(0.280-|.5| 4)$ & & & \\
\hline
\end{tabular}

Abbreviations: AGCT, adult granulose cell tumor; Cl, confidence interval; FIGO, International Federation of Gynecology and Obstetrics; HR, hazard ratio.

Complete staging surgery is recommended for patients with early-stage AGCT, ${ }^{5}$ and our results also suggested that staging surgery was beneficial in patients with early-stage AGCT. The recurrence rate was lower in patients with staging surgery compared with those without ( $12.5 \%$ vs $22.5 \%)$. Upstaging due to microscopic extraovarian disease has also been reported, ${ }^{6}$ and two patients were upstaged after

A

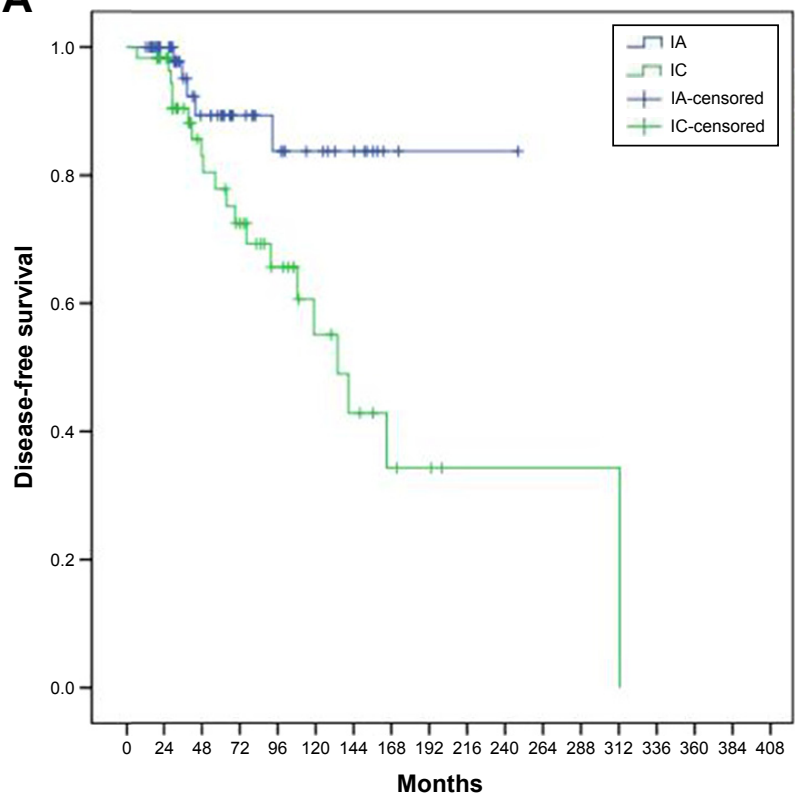

complete staging surgery, though the disease was confined to one ovary, which presented as apparent stage I disease. No patients with complete staging in the current study experienced recurrence or death during the follow-up period, compared with recurrences in 9 of $63(14.3 \%)$ patients who did not undergo complete staging. These results suggest that staging surgery is important in patients with presumed

B

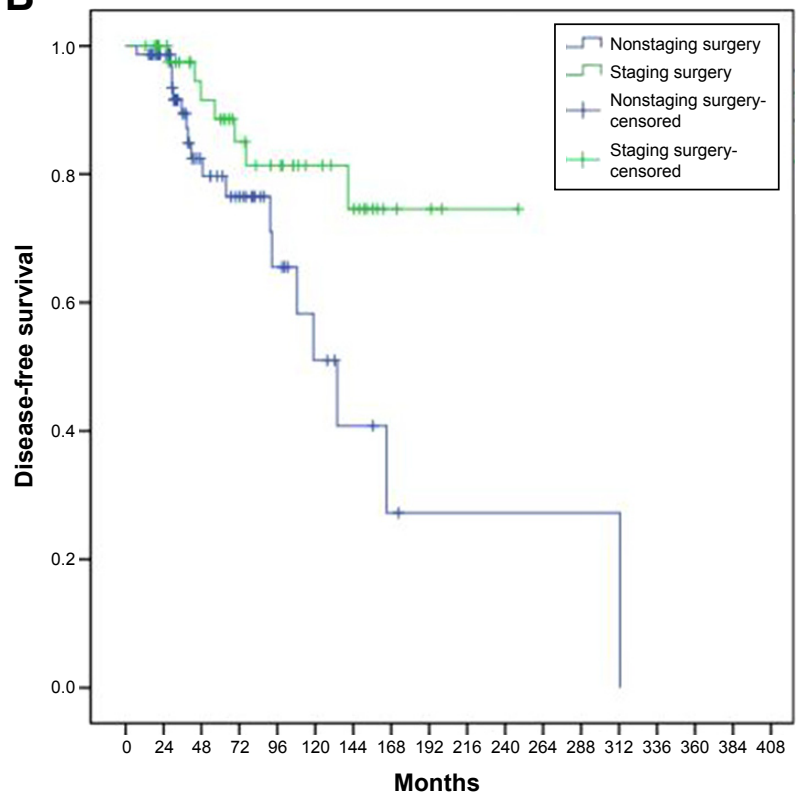

Figure I Disease-free survival in stage I AGCT patients according to FIGO stage (A) and surgical method (B). Abbreviations: AGCT, adult granulose cell tumor; FIGO, International Federation of Gynecology and Obstetrics. 
Table 4 Fertility surgery and pregnancy outcome in patients with AGCT

\begin{tabular}{|c|c|c|c|c|c|c|}
\hline & $\begin{array}{l}\text { Piura } \\
\text { et al, }{ }^{10} \quad 1994\end{array}$ & $\begin{array}{l}\text { Ayhan } \\
\text { et al," } 2009\end{array}$ & $\begin{array}{l}\text { Lee et al, } \\
2011\end{array}$ & $\begin{array}{l}\text { Lauszus } \\
\text { et al, }{ }^{12} 2014\end{array}$ & Present study & Total \\
\hline Total number & 18 & 80 & 113 & 163 & 141 & 515 \\
\hline Fertility sparing & 6 & 8 & 36 & 35 & 54 & 139 \\
\hline Type of surgery & USO: 6 & $\begin{array}{l}\text { USO + staging } \\
\text { surgery: } 8\end{array}$ & $\begin{array}{l}\text { Cystectomy: } 3 \\
\text { USO: } 27 \\
\text { USO + staging surgery: } 6\end{array}$ & USO: 35 & $\begin{array}{l}\text { Cystectomy: } 5 \\
\text { USO: } 40 \\
\text { USO + staging surgery: } 9\end{array}$ & $\begin{array}{l}\text { Cystectomy: } 8 \\
\text { USO: } 108 \\
\text { USO + staging surgery: } 23\end{array}$ \\
\hline Recurrence rate & $33.3(2 / 6)$ & $0(0 / 8)$ & NA & $25.7(9 / 35)$ & $26.0(14 / 54)$ & $24.3(25 / 103)$ \\
\hline $\begin{array}{l}\text { Postoperative } \\
\text { pregnancy, \% }\end{array}$ & $50(3 / 6)$ & $25(2 / 8)$ & $22.2(8 / 36)$ & $5.7(2 / 35)$ & $9.3(5 / 54)$ & $14.4(20 / 139)$ \\
\hline
\end{tabular}

Abbreviations: AGCT, adult granulosa cell tumor; USO, unilateral salpingo-oophorectomy; NA, not available.

early-stage AGCT. Surgeons should also aim to identify and excise extraovarian disease in patients with presumed early-stage disease. ${ }^{6}$

Surgery is the primary treatment for AGCT. GCT often affects younger patients, and fertility preservation is thus an important issue. However, the role of fertility-sparing surgery remains unclear. Some studies found that fertilitysparing management was associated with high recurrence and low survival rates, ${ }^{7,8}$ while others found no difference in recurrence rates between conservative and radical surgery in patients with stage I disease. ${ }^{2,9}$ In the current analysis, fertility-sparing surgery seemed to be a risk factor for recurrence in AGCT (32.6\% vs 13.3\%); however, further analysis of the 54 patients who received fertility-sparing surgery revealed that most recurrences occurred in patients who did not undergo staging surgery $(28.9 \%, 13 / 45)$, while the recurrence rate in those who did undergo staging was only $11.1 \%$ (1/9). Eighty-three patients underwent radical surgery, with a recurrence rate of $13.3 \%$. The recurrence rate of $11.1 \%$ in younger patients with fertility-sparing and staging surgery was thus acceptable compared with that of $13.3 \%$ in patients receiving radical surgery. These findings reinforce the importance of staging surgery in patients who want to retain fertility.

We also performed a literature search for information on pregnancy outcomes in patients received fertility-sparing surgery using PubMed, with the keywords: fertility sparing and pregnancy and granulosa cell tumor and ovary. We identified four articles that met the inclusion criteria. ${ }^{5,10-12}$ The cumulative data regarding pregnancy outcomes and recurrence rates in patients with AGCT after fertility-sparing surgery are summarized in Table 4. A total of 139 of 515 patients underwent fertility-sparing procedures, with recurrence rates of $0 \%-33.3 \%$. Only $14.4 \%(20 / 139)$ of patients had pregnancies after fertility-sparing surgery. Both our results and those of the previous studies suggested that recurrence was common in patients with fertility-sparing surgery, and close monitoring is therefore needed in these patients. Furthermore, hysterectomy and salpingo-oophorectomy are strongly recommended after completion of family planning.

Previous studies reported incidences of retroperitoneal lymph involvement during initial surgery of $0 \%-12.5 \%{ }^{6,13}$ A total of eight papers each reported more than 50 cases of AGCT, 1,2,4,6,11,13-15 and the summarized results indicate that the incidence of lymph node metastasis was only $3.9 \%$ (Table 5). In accord with previous reports, we found no cases of lymph node metastasis among 52 patients with nodal tissue evaluation. Karalok et $\mathrm{al}^{4}$ reported the highest rate of lymph node dissection in patients with AGCT to date, and showed that among 121 of 158 (76.6\%) patients with systematic lymph node dissection, only three had lymph node metastasis. In addition, lymphadenectomy was not associated with recurrence. These findings suggest that the incidence of lymph node metastasis is extremely low in AGCT at primary surgery, and lymphadenectomy may thus be omitted during staging surgery.

The patients may develop hyperplasia or endometrial cancer as a result of prolonged exposure to high levels of estradiol secreted by the GCT, with reported incidences

Table 5 Incidence of nodal involvement in studies reporting more than 50 cases

\begin{tabular}{|c|c|c|}
\hline Study & $\begin{array}{l}\text { Total cases } \\
\text { (years) }\end{array}$ & $\begin{array}{l}\text { Nodal involvement } \\
\text { in initial surgery }\end{array}$ \\
\hline Ertas et al' & $108(199 \mid-2010)$ & $3 / 58(5.1 \%)$ \\
\hline Mangili et $\mathrm{al}^{2}$ & 97 (1965-2008) & $0 / 15(0 \%)$ \\
\hline Karalok et al ${ }^{4}$ & $158(1988-2013)$ & $3 / 121$ (2.5\%) \\
\hline Park et $\mathrm{al}^{6}$ & $93(199 \mid-2010)$ & $0 / 25(0 \%)$ \\
\hline Nosov et $\mathrm{al}^{13}$ & 67 (1974-2004) & $4 / 32(12.5 \%)$ \\
\hline Abu-Rustum et al ${ }^{14}$ & $64(197 \mid-2005)$ & $0 / 16(0 \%)$ \\
\hline Brown et $\mathrm{al}^{15}$ & $178(1985-2005)$ & $0 / 36(0 \%)$ \\
\hline Ayhan et al" & $80(1982-2006)$ & $7 / 80(8.8 \%)$ \\
\hline Present study & $14 \mid(1983-2015)$ & $0 / 52(0 \%)$ \\
\hline Total & 986 & I7/435 (3.9\%) \\
\hline
\end{tabular}

Note: Range of years represent study periods. 
of endometrial hyperplasia and endometrial cancer of $21.5 \%-71 \%$ and $1.3 \%-13.2 \%$, respectively. ${ }^{16}$ Sixteen patients $(11.3 \%)$ in the current study had endometrial hyperplasia and two had endometrial cancer $(1.4 \%)$ at diagnosis of GCT, which was similar to previous report. ${ }^{16}$ Current guidelines for the treatment of GCT recommend comprehensive staging surgery including total hysterectomy and bilateral salpingooophorectomy in postmenopausal/postmenstrual women with AGCT. However, conservative surgery is always recommended in younger patients with a wish to maintain fertility if the tumor is confined to one ovary and the endometrium is normal. van Meurs et a ${ }^{17}$ studied endometrial abnormalities in 1,031 patients with GCT during long-term follow-up in a population-based cohort study. Among 490 patients who did not undergo hysterectomy at the time of GCT diagnosis, eight patients (1.6\%) developed hyperplasia and two $(0.4 \%)$ developed endometrial cancer. They concluded that the development of endometrial abnormalities after surgical removal of GCT was extremely rare and lower than the risk of endometrial cancer in the normal population. Furthermore, the endometrial abnormalities were accompanied with recurrence of GCT in 8 of the 10 patients. In our study, 54 patients underwent fertility-sparing surgery and no endometrial abnormalities were observed during follow-up. Fourteen of these patients suffered recurrence, but none developed endometrial lesions. This suggests that spontaneous regression may occur following the discontinuation of estrogen exposure by removal of the GCT. In addition, most patients (90\%) with endometrial hyperplasia or cancer were above 40 years old, consistent with a previous study ${ }^{16}$ which reported that endometrial pathology was rarely observed in GCT patients under the age of 40 years. Overall, these findings support the safety of conservative surgery in young patients wishing to retain fertility. However, given the common coexistence of endometrial abnormalities, it is important to evaluate the endometrium using ultrasound or curettage when considering conservative surgery in young patients.

In our study, $18.4 \%$ of patients with stage I disease had recurrence, with a mean time from initial surgery to relapse of 68 months (7-312 months). AGCT is characterized by slow, indolent growth with later recurrence. The longest diseasefree interval in the current study was 26 years, while the longest reported interval between initial diagnosis and recurrence was 37 years. ${ }^{18}$ Moreover, almost half of our patients $(46.2 \%, 12 / 26)$ had recurrence after more than 5 years. These findings highlight the importance of long-term follow-up of patients with AGCT, even those with early-stage disease.

The pelvis has been reported as the most common site of recurrence. ${ }^{19}$ The same result was seen in our study, the pelvis being the most common site $(69.2 \%, 18 / 26)$, followed by the abdomen $(38.5 \%, 10 / 26)$, lung $(7.7 \%, 2 / 26)$, and retroperitoneum $(7.7 \%, 2 / 26)$. There is currently no standard management for relapsed GCT, and multiple approaches such as surgery, chemotherapy, radiotherapy, and hormone therapies have been reported. ${ }^{20-22}$ All patients with recurrence in the current study received surgery, with or without other modalities: five patients underwent surgery alone, 18 underwent debulking surgery and chemotherapy, two received surgery and radiotherapy, and one received surgery and radiofrequency ablation. Mangili et a ${ }^{19}$ suggested that optimal debulking surgery was the cornerstone treatment for relapse of GCT. However, the absence of residual disease remained a prognostic factor, even at recurrence, and the 5-year overall survival rates from first recurrence were 55.6\% and $87.4 \%$ for patients with or without residual tumor at subsequent debulking surgery, respectively. Karalok et al ${ }^{23}$ reported on 16 patients with relapsed AGCT and showed that maximal debulking could be achieved in all patients with unifocal recurrence, compared with only three patients (37\%) with multifocal recurrence. They also found that multifocal recurrence and presence of disease were associated with poorer progression-free survival and overall survival, and concluded that maximum surgical effort is warranted for recurrent AGCT of the ovary. Chua et $\mathrm{al}^{20}$ demonstrated the feasibility and safety of peritonectomy to achieve maximal cytoreduction in patients with recurrent AGCT. In the present study, all patients underwent surgical debulking using multiple surgical approaches, such as extensive peritonectomy, diaphragmatic resection, and partial hepatectomy to achieve optimal cytoreduction. Sixteen patients remained alive without disease at the end of the follow-up period, four were alive with disease, two had died of disease, three were lost to follow-up, and one was undergoing treatment. The outcome of patients with relapsed AGCT thus seems acceptable, compared to that of ovarian epithelial cancer. Complete tumor resection appears to provide the best chance of patient survival, and surgeons should aim to excise recurrent foci.

The present study had some limitations. First, the rarity of GCT makes it hard to carry out well-designed studies. Second, this was a retrospective study conducted over a long period, and some information was missing as a result of loss of follow-up, while changes in practice patterns over the course of the study may also have affected the outcome. However, the present study also had several strengths. Notably, it was the first single-center study conducted in China, with a long follow-up period (median follow-up: 72.7 months). Furthermore, the number of cases $(n=141)$ represents one of the largest reported studies of patients with 
GCT, and all patients were handled by experienced gynecologic oncologists. Finally, in addition to AGCT outcomes, we also analyzed pregnancy results, which have rarely been reported in previous studies.

\section{Conclusion}

Most cases of AGCT are diagnosed at an early stage, but complete staging surgery is recommended for all patients with AGCT. Lymph node metastasis is rare among AGCT, and lymphadenectomy can thus be omitted from staging surgery. Unilateral salpingo-oophorectomy including staging surgery is the optimal treatment in younger patients who wish to retain fertility, with no compromise in terms of survival. In addition, it is important to carry out ultrasound or curettage to evaluate endometrial abnormalities in young patients considering conservative surgery. Maximal surgical resection is important for survival in patients with AGCT relapse, and lifetime follow-up is required, even in patients with early-stage disease, because of the risk of later recurrence.

\section{Acknowledgment}

We thank Susan Furness, PhD, from Liwen Bianji, Edanz Group, People's Republic of China (www.liwenbianji.cn/ac), for editing the English text of a draft of this manuscript.

\section{Author contributions}

All authors contributed toward data analysis, drafting and critically revising the paper and agree to be accountable for all aspects of the work.

\section{Disclosure}

The authors report no conflicts of interest in this work.

\section{References}

1. Ertas IE, Gungorduk K, Taskin S, et al. Prognostic predictors and spread patterns in adult ovarian granulosa cell tumors: a multicenter long-term follow-up study of 108 patients. Int J Clin Oncol. 2014;19:912-920.

2. Mangili G, Ottolina J, Gadducci A, et al. Long-term follow-up is crucial after treatment for granulosa cell tumours of the ovary. Br J Cancer. 2013; 109:29-34.

3. Wilson MK, Fong P, Mesnage S, et al. Stage I granulosa cell tumours: a management conundrum? Results of long-term follow up. Gynecol Oncol. 2015;138:285-291.

4. Karalok A, Turan T, Ureyen I, et al. Prognostic factors in adult granulosa cell tumor: a long follow-up at a single center. Int J Gynecol Cancer. 2016;26: 619-625.
5. Lee IH, Choi CH, Hong DG, et al. Clinicopathologic characteristics of granulosa cell tumors of the ovary: a multicenter retrospective study. J Gynecol Oncol. 2011;22:188-195.

6. Park JY, Jin KL, Kim DY, et al. Surgical staging and adjuvant chemotherapy in the management of patients with adult granulosa cell tumors of the ovary. Gynecol Oncol. 2012;125:80-86.

7. Pautier $\mathrm{P}$, Lhomme $\mathrm{C}$, Culine $\mathrm{S}$, et al. Adult granulosa-cell tumor of the ovary: a retrospective study of 45 cases. Int J Gynecol Cancer. 1997; 7: $58-65$.

8. Evans AT, Gaffey TA, Malkasian GD Jr, Annegers JF. Clinicopathologic review of 118 granulosa and 82 theca cell tumors. Obstet Gynecol. 1980; 55:231-238.

9. Zhang M, Cheung MK, Shin JY, et al. Prognostic factors responsible for survival in sex cord stromal tumors of the ovary: an analysis of 376 women. Gynecol Oncol. 2007;104:396-400.

10. Piura B, Nemet D, Yanai-Inbar I, Cohen Y, Glezerman M. Granulosa cell tumor of the ovary: a study of 18 cases. J Surg Oncol. 1994;55: 71-77.

11. Ayhan A, Salman MC, Velipasaoglu M, Sakinci M, Yuce K. Prognostic factors in adult granulosa cell tumors of the ovary: a retrospective analysis of 80 cases. J Gynecol Oncol. 2009;20:158-163.

12. Lauszus FF, Petersen AC, Neumann G, et al. Less extensive surgery compared to extensive surgery: survival seems similar in young women with adult ovarian granulosa cell tumor. Eur J Obstet Gynecol Reprod Biol. 2014;177:61-66.

13. Nosov V, Silva I, Tavassoli F, Adamyan L, Farias-Eisner R, Schwartz PE. Predictors of recurrence of ovarian granulosa cell tumors. Int J Gynecol Cancer. 2009; 19:628-633.

14. Abu-Rustum NR, Restivo A, Ivy J, et al. Retroperitoneal nodal metastasis in primary and recurrent granulosa cell tumors of the ovary. Gynecol Oncol. 2006;103:31-34.

15. Brown J, Sood AK, Deavers MT, Milojevic L, Gershenson DM. Patterns of metastasis in sex cord-stromal tumors of the ovary: can routine staging lymphadenectomy be omitted? Gynecol Oncol. 2009;113: 86-90.

16. Ottolina J, Ferrandina G, Gadducci A, et al. Is the endometrial evaluation routinely required in patients with adult granulosa cell tumors of the ovary? Gynecol Oncol. 2015;136:230-234.

17. van Meurs HS, Bleeker MC, van der Velden J, Overbeek LI, Kenter GG, Buist MR. The incidence of endometrial hyperplasia and cancer in 1031 patients with a granulosa cell tumor of the ovary: long-term follow-up in a population-based cohort study. Int J Gynecol Cancer. 2013; 23:1417-1422.

18. Hines JF, Khalifa MA, Moore JL, Fine KP, Lage JM, Barnes WA. Recurrent granulosa cell tumor of the ovary 37 years after initial diagnosis: a case report and review of the literature. Gynecol Oncol. 1996;60: 484-488.

19. Mangili G, Sigismondi C, Frigerio L, et al. Recurrent granulosa cell tumors (GCTs) of the ovary: a MITO-9 retrospective study. Gynecol Oncol. 2013;130:38-42.

20. Chua TC, Iyer NG, Soo KC. Prolonged survival following maximal cytoreductive effort for peritoneal metastases from recurrent granulosa cell tumor of the ovary. J Gynecol Oncol. 2011;22:214-217.

21. Wolf JK, Mullen J, Eifel PJ, Burke TW, Levenback C, Gershenson DM. Radiation treatment of advanced or recurrent granulosa cell tumor of the ovary. Gynecol Oncol. 1999;73:35-41.

22. Fishman A, Kudelka AP, Tresukosol D, et al. Leuprolide acetate for treating refractory or persistent ovarian granulosa cell tumor. $J$ Reprod Med. 1996;41:393-396.

23. Karalok A, Ureyen I, Tasci T, et al. Maximum surgical effort is warranted for recurrent adult granulosa cell tumors of ovary. Tumori. 2016;102: 404-408. 


\section{Publish your work in this journal}

OncoTargets and Therapy is an international, peer-reviewed, open access journal focusing on the pathological basis of all cancers, potential targets for therapy and treatment protocols employed to improve the management of cancer patients. The journal also focuses on the impact of management programs and new therapeutic agents and protocols on

patient perspectives such as quality of life, adherence and satisfaction. The manuscript management system is completely online and includes a very quick and fair peer-review system, which is all easy to use. Visit http://www.dovepress.com/testimonials.php to read real quotes from published authors.

Submit your manuscript here: http://www.dovepress.com/oncotargets-and-therapy-journal 